\title{
Pediatric Radiology Editorial Board - acknowledgements and updates
}

\author{
Peter J. Strouse • Guy Sebag
}

Received: 20 November 2013 / Accepted: 21 November 2013 / Published online: 30 November 2013

(C) Springer-Verlag Berlin Heidelberg 2013

In the front of this journal you can find a listing of the Editorial Board members of Pediatric Radiology. Individuals serve on the Editorial Board due to their expertise and experience in subject matter, due to their established record of excellence in reviewing, and in recognition of other contributions to the journal. Although most of our Editorial Board is composed of pediatric radiologists, we also engage some nonradiologist physicians, physicists and others whose expertise is frequently pertinent to imaging.

Editorial Board membership is not honorary. The Editorial Board of Pediatric Radiology is a working editorial board. Editorial Board members are called upon for a greater number of reviews and for reviews on papers that are challenging and controversial or obscure in nature. When we are challenged as editors to find reviewers for a paper, the Editorial Board steps up. When initial reviews are conflicting, an additional expert opinion from an Editorial Board member may be sought.

In addition to reviews, members of the Editorial Board are expected to contribute in other ways. As subject matter experts, Editorial Board members assist the editors as consultants and by identifying new re-

P. J. Strouse $(\bowtie)$

Section of Pediatric Radiology,

C. S. Mott Children's Hospital, Room 3-231,

Department of Radiology,

University of Michigan Health System,

1540 E. Hospital Drive,

Ann Arbor, MI 48109-4252, USA

e-mail: Rad-Ped-Radiol-Journal@med.umich.edu

G. Sebag

Service d'Imagerie Pédiatrique, Hôpital Robert Debré,

48, Boulevard Sérurier, Paris, France 75019 viewers to add to our team. Editorial Board members are asked to contribute commentaries on important and controversial articles. Editorial Board members are asked to contribute to the journal in the form of review articles, mini-symposia and other special projects. Ideally, each radiologist on the Editorial Board contributes content in such a manner at least once every 3-5 years. Such contributions, of course, are not gratuitous - they go through the standard review process.

A new category of "Child Abuse" has been added within the Editorial Board. This is warranted by the volume of manuscripts received on child abuse and related topics and by the challenges encountered in this area. Imaging of child abuse and its differential diagnoses is an important and sometimes controversial topic. We are very fortunate to have several experts on the imaging of child abuse and its differential diagnoses to include under this heading.

Composition of the Editorial Board of Pediatric Radiology is re-evaluated and updated on a yearly basis, the new board taking effect with the January issue of each volume (year). Service is not term-limited.

The editorial team is extremely grateful to our Editorial Board members for their important contributions to the journal. Success of the journal is dependent on the expertise, guidance and contributions of the community of experts in pediatric imaging and related subjects. We would like to sincerely thank the following departing Editorial Board members for their years of excellent service to the journal:

Paul Babyn, Saskatoon (General Pediatric Radiology)

Peter Brader, Graz (Genetics-Molecular Imaging)

Eric Effmann, Seattle (Chest)

Richard Fotter, Graz (Uroradiology)

Max Hassan, Paris (Book Reviews) 
Gary Hedlund, Salt Lake City (Neuroradiology)

Carlos Sivit, Cleveland (Gastrointestinal)

We would like to welcome the following incoming Editorial Board members:

Monica Epelman, Orlando (General Pediatric Radiology) Robert MacDougall, Boston (Technology)
Harriet Paltiel, Boston (Uroradiology)

Vincent Palusci, New York (Child Abuse)

Jeannette Perez-Rossello, Boston (Child Abuse)

Michael Riccabona, Graz (Uroradiology)

Iwan Roberts, Sheffield (Book Reviews)

Karen Rosendahl, Bergen (Musculoskeletal)

Samuel Stafrace, Aberdeen (Education)

Stavros Stivaros, Manchester (Book Reviews) 